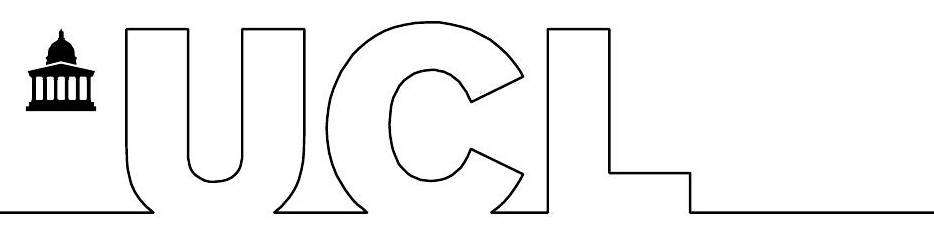

Maggs, G; Nicoll, M; Zuël, N; White, PJC; Winfield, E; Poongavanan, S; Tatayah, V; (2015) Rattus management is essential for population persistence in a critically endangered passerine: Combining small-scale field experiments and population modelling. Biological Conservation , 191 (C) pp. 274281. 10.1016/i.biocon.2015.06.039. (In press). Downloaded from UCL Discovery:

http://discovery.ucl.ac.uk/

\title{
ARTICLE
}

\section{Rattus management is essential for population persistence in a critically endangered passerine: Combining small-scale field experiments and population modelling.}

Gwen Maggs ${ }^{a, b *}$, Malcolm Nicoll ${ }^{a}$, Nicolas Zuël ${ }^{c}$, Patrick, J. C. White ${ }^{d}$, Edward Winfield $^{c}$, Sanda Poongavanan ${ }^{c}$, Vikash Tatayah ${ }^{c}$, Carl, G. Jones $^{c, e}$ \& Ken Norris ${ }^{a}$

${ }^{a}$ Institute of Zoology, Zoological Society of London, Regent's Park, London, NW1 4RY, United Kingdom

${ }^{b}$ Department of Genetics, Evolution and Environment, University College London, Darwin Building, Gower Street, London, WC1E 6BT

${ }^{c}$ Mauritian Wildlife Foundation, Grannum Road, Vacoas, Mauritius

${ }^{d}$ Edinburgh Napier University, School of Life, Sport and Sciences, Sighthill Campus, Edinburgh, EH11 4BN, United Kingdom

${ }^{e}$ Durrell Wildlife Conservation Trust, Les Augrès Manor, Trinity, Jersey, JE3 5BP, Channel Islands

${ }^{*}$ Corresponding author. E-mail: Gwen.Maggs@ioz.ac.uk

\begin{abstract}
Invasive species are a major threat for island biodiversity, causing species decline and extinction globally. Of all invasive mammals rats are one of the most detrimental and have been the target of numerous control and eradication programmes. In Mauritius rats have contributed to the extinction of $50 \%$ of the island's fauna and are thought to be the main threat to the endemic Mauritius olive white-eye (Zosterops chloronothos), a critically endangered passerine. Assessing the impact of rats and suitable control strategies is often problematic in such cases because of the lack of replicate populations for experiments. Here, we illustrate how to overcome this issue by combining a small-scale rat management experiment on olive white-eyes with demographic models that provide estimates of the potential effects of management on vital rates and population growth. We established poison and trapping grids within breeding territories, and show that rat management significantly decreased rat abundance and increased nesting success. An individual-based stochastic simulation model suggested that rat control could produce a 5-6 fold increase in the annual productivity of female olive white-eyes, which in turn would be sufficient to stabilise population growth. In the absence of rat control, our analysis suggests the olive white-eye population will decline by about $14 \%$ per annum. By combining low cost field experiments with widely available demographic models we highlight the value of targeted, effective rat management techniques for both short and long-term population management in threatened passerines.
\end{abstract}

Keywords: Passerine, Rattus, Predator control, Nesting success, Annual productivity, Population growth. 


\section{Introduction}

Since the $15^{\text {th }}$ century invasive species have been partly or wholly responsible for the extinction of at least 65 bird species making them the greatest threat to avifauna, especially on islands where predation is a major cause of extinction (Atkinson, 1985; Birdlife International, 2004; King, 1985). Having reached around $90 \%$ of all islands rats have been identified as a 'massive' global threat under a new classification system based on the IUCN Global Invasive Species Database with Rattus rattus (ship or black rats) having the greatest detrimental effects on island bird populations (Atkinson, 1989, 1985, 1977; Blackburn et al., 2014; Towns et al., 2006).

The eradication of rats from islands is now a widely used conservation tool benefiting numerous taxa (Towns et al., 2006), with 344 successful eradications of ship rats and $R$. norvegicus (brown rats) from islands between 1951 and 2011 (Island Conservation, 2012). In contrast to rat eradications from unpopulated islands, the control of rats in areas on large populated islands remains challenging, however, the local extirpation of rats through the establishment of rat-free areas using poison and trapping is one possible solution. To date these have been implemented with varying degrees of success for many island passerine species threatened by rats where marooning on predator free islands is not an option but the creation of rat-free areas is a viable long-term solution e.g. Cook Islands, Hawaii, New Zealand, Seychelles and Tahiti (Blanvillain et al., 2003; Innes et al., 1999; Rocamora and Baquero, 2007; Robertson et al., 1994; Trent et al., 2008; Vanderwerf and Smith, 2002). However, one of the challenges faced by this approach is quantifying the degree (and duration) to which rat populations can be suppressed (or eradicated) and the apparent benefits of this management to improve the viability of threatened bird populations in both the short and long-term (Innes et al., 1999; James and Clout, 1996; Moorhouse et al., 2003).

Identifying any measurable benefits of management is in itself challenging as it requires observing individuals through whole seasons and individual identification. For multi-brooded passerines this challenge is compounded due to their ecology and behaviour compromising our ability to collect annual individual-based data and accurately assess the benefits (Bottrill et al., 2008; Pease and Grzybowski, 1995). Here we deal with these challenges by combining a small scale field experiment, investigating the impact of rat management on nesting success, with an individual-based stochastic simulation model to predict annual productivity and a population matrix model to assess the population-level consequences of management. These techniques have been applied successfully for other threatened passerine species investigating species responses to management actions using field experiments spanning numerous years (Armstrong et al., 2006; Basse et al., 2003; Brook and Kikkawa, 1998; Fessl et al., 2010). However, here we investigate the impacts of smallscale, short-term management actions combined with demographic models to obtain quick results for species management; which for critically endangered populations is vital.

In the Zosterops genus ship rats are considered a threat to $70 \%$ of the endangered or critically endangered species all of which are situated on islands (Mauritius, Norfolk Islands, Northern Mariana Islands, Sangehi and Seychelles), they are also thought to be the main cause of the robust white-eye (Zosterops strenuus) extinction (Birdlife International, 2015, 2004; IUCN, 2014). The Mauritius olive white-eye (Zosterops chloronothos) (hereafter referred to as the olive white-eye) is one of four white-eye species currently classed as critically endangered and is in the top $10 \%$ of the Evolutionary Distinct and Globally Endangered (EDGE) bird species list (IUCN, 2013; Jetz et al., 2014).

Within Mauritius the olive white-eye is the rarest of the remaining nine endemic land bird species, with a limited understanding of its basic ecology (Nichols et al., 2005; Safford, 1991; Safford and Hawkins, 2013; Staub, 1993). The species has experienced an island wide decline due to habitat loss, competition with introduced bird species and suspected nest predation (eggs and nestlings) by ship rats (Nichols et al., 2005; Safford, 1997a; Safford and Hawkins, 2013). Between 1975 and 2001 the population declined from 340-350 pairs to 93- 
148 and is now primarily restricted to an area less than $25 \mathrm{~km}^{2}$ in the Black River Gorges National Park (Fig. 1) (Cheke, 1987; Nichols et al., 2004). In response to the population decline a recovery project was initiated in 2005 , which involved the establishment of a subpopulation on a rat-free island nature reserve (lle aux Aigrettes, $20^{\circ} 42^{\prime} \mathrm{S} 57^{\circ} 7^{\prime} \mathrm{E}$ ), the monitoring of a remnant sub-population in the National Park and the control of rats (Cole et al., 2008, 2007; Maggs et al., 2010, 2009).

The recovery project used rat control measures in the mainland population using rat snaptraps around individual nesting sites from 2006 to 2010 . However, this sporadic management was unable to identify if rats are a major limiting factor for the breeding population or whether management could effectively control them. Here we examine, using an experimental framework, if rats are a threat to the mainland olive white-eye population and whether the management of rats through poisoning/trapping can reduce their impact by combining a small-scale field experiment with demographic models. Specifically, we examine if (i) the application of poison reduces rat abundance, (ii) the management of rats leads to an improvement in nesting success, (iii) an observed increase in nesting success can significantly improve annual productivity, and (iv) an increase in productivity can have a biological impact on the rate of population change and prevent population decline. Based on our findings we demonstrate how small-scale, short-term field experiments in conjunction with demographic models can provide an insight into the long-term benefits of controlling nest predators such as rats for threatened passerine populations.

\section{Methods}

2.1 Study Site and Species

The olive white-eye population has a very restricted range, and within this range, a very patchy distribution with low densities. Combo $\left(20^{\circ} 466^{\prime} S 57^{\circ} 51^{\prime} \mathrm{E}\right)$, the chosen study site, is an area of c.5 km in the Black River Gorges National Park where the highest density of olive white-eye breeding pairs remain, estimated at 25-30 breeding pairs (Nichols et al., 2004; Fig. 1). Combo has a riparian upland forest habitat with degraded vegetation supporting populations of four other endemic bird species (Safford, 1997b).

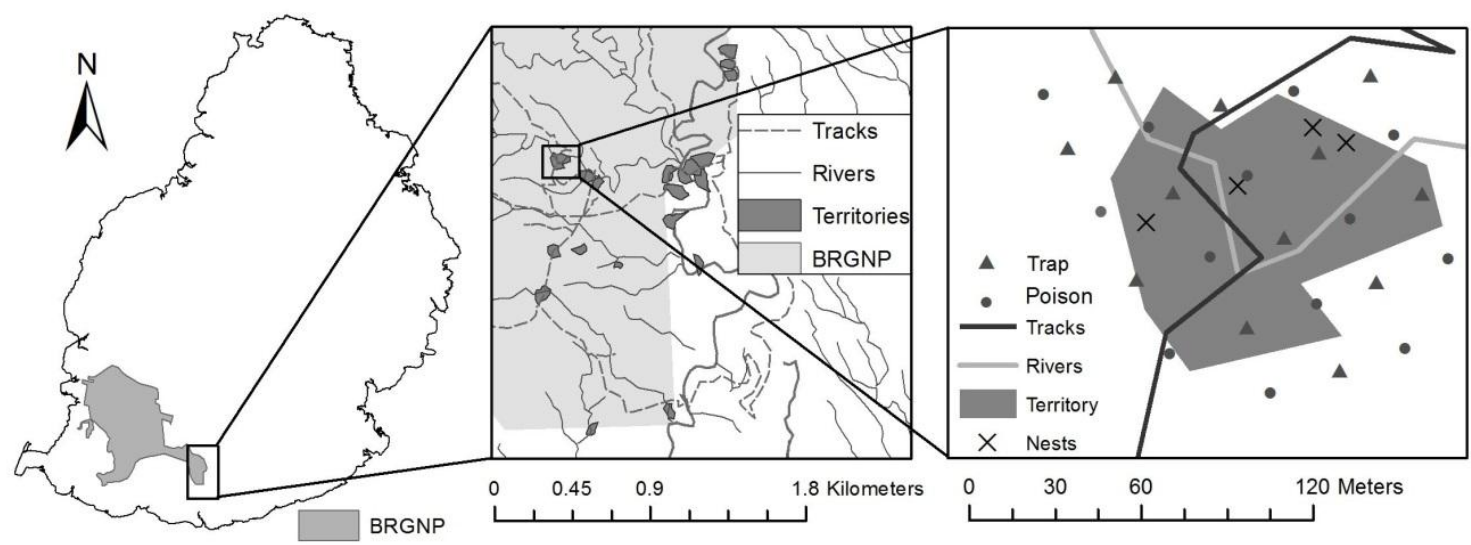

ig. 1. The location of the Black River Gorges National Park (BRGNP) in Mauritius (left), Mauritius olive white-eye breeding territories in the Combo region in the Southwest of the National Park (middle) and a schematic representation of a poison and trapping grid across an olive white-eye breeding territory (right).

The olive white-eye is part of an ancient Indian Ocean white-eye lineage with birds colonising from Asia prior to the subsequent evolution of the African species (Warren et al., 2006). Prior to 2001 little was known about the olive white-eye with only eight nesting episodes where eggs were laid, ever recorded; of which only one successfully fledged nestlings (Nichols et al. 2005; Safford 1991; Staub 1993). 
However, through the management and monitoring of the Combo population and the establishment of the lle aux Aigrettes island sub-population the life-history of the species is now better documented (Cole et al., 2008, 2007; Maggs et al., 2011, 2010, 2009).

Olive white-eye pairs are monogamous and in the wild defend territories of c. 0.5 ha $( \pm 0.2, n=21)$ which characteristically include running water sources, an area of canopy and open areas (Cole et al., 2008; Maggs et al., 2011; Nichols et al., 2005; Safford and Hawkins, 2013). The breeding season is in the austral summer, typically between August and March. They are a multi-brooded species and will breed continuously throughout the season, regardless of whether their nests succeed or fail; building a new nest with each attempt and reaching up to seven nesting attempts, which may be abandoned before eggs are laid, in one breeding season (Cole et al., 2008; Maggs et al., 2011). The open cup nests take 3-13 days $(n=41)$ to build and are situated high in the canopy on thin outer branches (average nest height of $10 \mathrm{~m} \pm 4.5, \mathrm{n}=55$ ), which makes accessing nests logistically challenging and in many cases impossible (Cole et al., 2008; Maggs et al., 2011, 2010, 2009). Females lay 1-3 pale blue eggs, which are then incubated for 12 days by both the male and female (Cole et al., 2007; Nichols et al., 2005). Nestlings are fed invertebrates by the pair for 14 days until fledging after which the juveniles will remain with the adults for 2-8 weeks before reaching independence (Nichols et al., 2005; Safford and Hawkins, 2013).

The remnant wild population is un-ringed and the habitat means that accurate data on breeding biology and survival is difficult to obtain, however, the ringed population on Ile aux Aigrettes provides detailed demographic data which can be applied to the wild population. On lle aux Aigrettes, where there are no mammalian predators and the population is supplementary fed, the mean egg hatching rate is 1.2 nestlings per nest $(n=47)$ and the mean nestling fledging rate in successful nests is 1.3 fledglings per nest $(n=14)$ (see online Appendix 2). Juvenile survival (i.e. first year) is estimated at 0.63 (approx. 95\% C.I. $=0.23-0.86$ ) and annual adult survival at 0.81 (approx. 95\% C.I. $=0.72-0.87$ ) (see online Appendix 1). Although rats are considered a threat to nesting success in the mainland population, there is no physical or incidental evidence to indicate that adults are predated on the nest. The breeding pairs on the mainland are monitored closely throughout the breeding season and although not ringed their monogamous behaviour allow missing birds to be recorded. Adult olive white-eye have very few natural predators except for possibly the Endangered Mauritius kestrel (Falco punctatus) which is not yet found in the Combo region.

\subsection{Rat Management}

Between July 2010 and March 2011 an experiment was conducted to explore the impact of poisoning on rat abundance and the impact of different levels of rat management on olive white-eye nesting success. During this time 24 known olive white-eye breeding territories were present in the Combo region, 21 of which were included in the experiment. Each of the 21 breeding territories were randomly assigned one of three levels of rat management; 'Control' (no management) $(n=7)$, 'Trap' (snap-trapping alone) $(n=7)$ and 'Poison' (rat poisoning and snap-trapping) (n $=7$ ). Management techniques were targeted at the two rat species present in Mauritius: ship and brown rats.

Grids were established across breeding territories assigned to Trap and Poison management prior to the breeding season, covering the breeding territory of each individual pair with 25 m intersections (Fig. 1) (Vanderwerf et al., 2011). Snap-traps were placed every $50 \mathrm{~m}$ across the grids and trapping commenced prior to poisoning 
(July) to identify initial rat abundance. Trapping was then conducted every other month (Sept, Nov, Jan) to generate an index of rat abundance throughout the breeding season under Trap management (without poison) and Poison management (with poison) to investigate the impact of poison on rat abundance. Snap-traps were set for three consecutive nights and checked and re-set daily following the methods of Cunningham and Moors (1996). In territories under Poison management bait stations were installed every $50 \mathrm{~m}$ at alternative points to the snap-traps using a 'Hockey Stick' station design (Tatayah et al., 2007a; Fig. 1). Poison was initiated following the first round of snap-trapping, one month before breeding activity began using $20 \mathrm{~g}$ Megalon Wax Blocks, a fixed Bromadiolone based poison which prevents rats from removing and hoarding poison and encourages consumption (INDIA, 2013). The poison grids were maintained continuously throughout the breeding season and re-baited on a weekly basis. Secondary poisoning is a potential threat when using rat poison but no non-target mammals or birds were observed consuming poison. However, gastropods were observed, but were excluded from the bait stations with the use of copper wire around the entrances (Tatayah et al., 2007b).

\subsection{Nest Monitoring}

Since the initiation of the recovery project in 2005 breeding territories in Combo have been monitored at the start of every season prior to breeding activity in order to identify pairs and define territories. Although the birds are un-ringed missing birds can be identified through the monogamous behaviour of the pairs and our close observations allow us to see gaps in the nesting cycle or breeding behaviour; in the 2010/11 season there were no pair or territory changes. Between August and February 2010/11 all 21 territories involved in the field experiment (Control, Trap and Poison) were monitored for nesting activity with searches commencing prior to the breeding season to find the first attempts; which assisted in subsequent nest finding. Due to the cryptic and elusive behaviour of the breeding pairs and the challenging terrain territories were visited at least twice a week and searched for a maximum of one hour.

If a nest was located, nest habitat data was collected, this included nest characteristics (nest height $(\mathrm{m})$, position in canopy and density of vegetation around the nest) and vegetation structure (understory density and canopy density). Ship rats are known to use the thick canopy and dense understory to move around their home range which could increase the chances of opportunistic predation of nests (Hall, 2003). The nest habitat data enables these additional influencing factors to be investigated against breeding success. Nests were monitored every three days for a maximum of one hour, to determine nest status, until nest outcome. Due to the inaccessible positioning of nests in Combo all activity was recorded through behavioural observation (Nichols et al., 2005). Through these observations and associated searches fledgling rates were obtained; as fledglings stay within a close proximity to the nest for 1-2 days (Safford and Hawkins, 2013). Nests were classed as failed if no breeding activity was seen at the nest for four consecutive nest watches or if a new nest was discovered.

\subsection{Statistical Analysis}

All our analyses were conducted in R version 3.0.1 (R Core Team, 2013).

\subsubsection{Rat Abundance}

We wished to assess whether rat poisoning in addition to snap-trapping could significantly reduce rat abundance within olive white-eye breeding territories across a breeding season. To do this, we first calculated the catch per unit effort (CPUE) (for both rat species combined) of snap-traps for each territory under Trap or Poison management during each trapping episode using the methods of Nelson and Clark 
(1973); which accounts for sprung traps. No absolute control was available for the analysis (which would have to be done with non-lethal monitoring methods, e.g. tracking tunnels) and the territories under Control management, used for monitoring nesting activity, were not included as these had no measure of rat abundance.

Using the CPUE data we tested the impact of poison on rat abundance across the breeding season exploring the month to month variation using a generalized linear mixed effects model (GLMM) in the package 'Ime4' (Bates et al., 2013). The model contained a response variable of CPUE per territory per month, categorical fixed effects of month (July, Sept, Nov, Jan), poison present (Yes/No) and their interaction and random effects of area, a continuous variable (to account for unintended variations in the density of traps and poison stations), and territory, a categorical variable (accounting for repeated data from each breeding territory throughout the breeding season). The model was run with and without the interaction and also with and without area comparing them separately in a two-way analysis of variance to test how the CPUE responded to the presence/absence of poison and variations in the density of treatments. To test for any significant change in the CPUE at two, four and six month intervals following the initiation of poison, individual models were run comparing each post poisoning month (Sept, Nov, Jan) with the pre-poisoning month (July).

\subsubsection{Nesting Success}

A total of 40 nesting attempts, where at least on egg was laid, were monitored and these were evenly distributed across the three rat management treatments; Control $(n=15)$, Trap $(n=12)$ and Poison $(n=13)$. Nests were not monitored on a daily basis and so the nest outcome date was classed as the midpoint between the last and penultimate observation (Mayfield, 1961). Failure dates were rounded up to the nearest day (Hazler, 2004). To compare daily nest survival between rat management treatments we used Mayfield logistic regression (Hazler, 2004) within a GLMM framework (Ludwig et al., 2012). This approach removes bias caused by unrecorded failed nests and the stage at which nests were found (Mayfield, 1975, 1961). We constructed separate models for daily nest survival during the incubation $\left(D_{N} S_{1}\right)$ and nestling $\left(D N S_{N}\right)$ periods because the impact of rat management on nest survival might be stage-specific.

Each model contained a response variable of daily nest survival, combining 'trials' (the days of exposure for each nest) and 'events' ( 0 = success, 1 = failure) using the 'cbind' function in R (Hazler, 2004; Ludwig et al., 2012). Rat management was included as a categorical fixed effect and individual olive white-eye territories as a categorical random effect (accounting for repeated data (nesting attempts) from each breeding territory throughout the breeding season). We compared this model with a null model in a two-way analysis of variance to assess the statistical significance of the rat management variable. We also explored models in which rat management treatments were compared separately (Control, Trap and Poison) and combined (Control, Trap + Poison) to assess the statistical evidence for an effect of poisoning alone on nest survival. Formally, our models are based on daily failure rates, so we transformed parameter estimates to visually display $D N S_{\text {, }}$ and $D N S_{N}$.

Due to the small sample of nests available for analysis it is possible that an apparent statistically significant effect of rat management on nest survival might be due to other factors in relation to additional nest characteristics or vegetation structure. Our small sample size precluded the fitting of complex multivariate GLMMs, so to check for any potential confounding effects we simply compared a range of measures of nesting habitat between rat management treatments. These measures included nest characteristics, nest height $(\mathrm{m})$, position (position in canopy: upper, middle, lower) 
and density (density of vegetation around the nest: dense, sparse) and vegetation structure, understory (understory density: dense, medium, sparse) and canopy (canopy density: dense, medium, sparse). These additional categorical and continuous measures were run against the rat management categorical factor in individual Chi-squared tests to identify any effect. However, there is a limitation to this approach, if additional effects are identified using this method it will be unclear whether they are independent of any effects found via the GLMM model.

\subsubsection{Annual Productivity}

For demographic projections of management treatments, effects on nesting success needed to be translated to effects on annual productivity (number of fledglings produced per female per season). In multi-brooded species a direct estimate of annual productivity typically requires intensive studies of marked females through an entire season (e.g. Weggler, 2006). Due to the limited number of breeding pairs, the challenges of nest finding, limited staffing and un-ringed individuals a direct estimate of olive white-eye annual productivity in Combo could not be made without creating bias. Instead we took the more frequently used approach of its estimation via a dynamic seasonal productivity model (see review by Etterson et al., 2011).

We used an individual-based stochastic simulation model developed to study predator effects in multi-brooded passerines (White, 2009) based on previous models (Beintema and Muskens, 1987; Powell et al., 1999). The model follows a simulated female on a 'random' walk through a season, selecting randomly from pre-specified distributions of parameters that limit the season (first-egg date, re-nesting probability) or determine breeding success (clutch size, hatching probability, fledging probability, $\mathrm{DNS}_{\mathrm{l}}, \mathrm{DNS}_{\mathrm{N}}$ ), and using temporal duration parameters that determine the length or maximum length (in days) of the seasonal components (nest building, inter-attempt intervals, maximum incubation period, maximum nestling period, maximum number of successful nests) (Table 1). All the methods used to generate these parameters can be found in online Appendix 2.

Table 1.

Biological parameters and their values used in calculating the mean annual productivity of breeding female Mauritius olive white-eye under differing rat management techniques; Control (No management), Trap (Snap-trapping alone) and Poison (Rat poisoning and snaptrapping).

\begin{tabular}{lcc}
\hline \multicolumn{1}{c}{ Parameter } & Value \\
\hline Initial first egg date (days) & 60 \\
Daily nest survival during incubation & Control & 0.942 \\
(DSN ${ }_{\mathrm{I}}$ ) & Trap & 0.995 \\
& Poison & 0.956 \\
Daily nest survival during nestling & Control & 0.845 \\
$\left(\right.$ DNS $\left._{\mathrm{N}}\right)$ & Trap & 0.925 \\
& Poison & 0.977 \\
Building duration (days) & & $3-13$ \\
Maximum number of successful & 7 \\
nests & & 12 \\
Incubation period (days) & & 14 \\
Nestling period (days) & & 1.206 \\
Mean eggs hatching per nest & 1.357 \\
Mean nestlings fledging per nest & $1-3$ \\
Clutch size & & Fig. A1. \\
Re-nesting probability following & \\
success & & \\
\hline
\end{tabular}


Stochastic simulation models are capable of simulating 're-nesting compensation' which occurs because birds that fail may be able to make more attempts than those that are successful (Grzybowski and Pease, 2005). Re-nesting compensation is expected to dampen the effect of inter-individual or inter-population variation in nest success on seasonal productivity (Nagy and Holmes, 2004). This has important implications for a management study such as this, because it means that apparently large responses observed in nest success may not necessarily translate into biologically significant responses at the level of annual productivity or at the population level. The non-independence of nest success and number of attempts made also means that assuming a fixed number of attempts is ultimately biased (Grzybowski and Pease, 2005). Dynamic models can address the lack of information on number of attempts by constraining the number of attempts individually and indirectly via the inclusion of a re-nesting probability function, which describes the probability at any point in the season that a bird will continue to nest after a failed or successful attempt (Table 1; Fig. A1; online Appendix 2) (Etterson et al., 2009; Mattsson and Cooper, 2007; Pease and Grzybowski, 1995).

For each rat management scenario we simulated 10000 females and extracted their annual productivity estimates. Model sensitivity testing was carried out using the Control management as a base model with each parameter adjusted by $\pm 20 \%$. The average effect sizes were estimated along with 95\% confidence intervals comparing Poison and Trap management against Control and enabling a comparison of the rat management impact on a biological rather than statistical basis (Corell et al., 2012; Underwood, 1997; White et al., 2013). Replication determines statistical power and so testing statistical significance may be inappropriate for simulation data (White et al., 2013).

\subsubsection{Population Multiplication Rate}

When investigating the impact of management on population persistence many studies have used population viability analysis (PVA) (Armstrong et al., 2006; Basse et al., 2003; Fessl et al., 2010). However, with limited data availability a concern is that there is not enough qualitative and quantitative data for a reliable analysis even with expert input (Brook and Kikkawa, 1998). A study investigating Capricorn silvereyes (Zosterops lateralis chlorocephala) on Heron Island showed that the minimum dataset required to gain an accurate estimate of underlying population parameters was fifteen years and that there is a danger of less costly but seriously deficient management schemes being implemented based on unrealistic or overly optimistic PVA predictions (Brook and Kikkawa, 1998). Due to the rarity of the olive white-eye there is still limited data and no understanding of how the key demographic parameters are influenced by environmental conditions and other stochastic events. Therefore, if a PVA was used predictions would be made on inadequate and insufficient data. Instead a population multiplication rate (PMR) was calculated to explore the potential long-term impact of rat management on population growth of the mainland olive white-eye under different rat management treatments.

To calculate the PMR, we used a two-stage (yearling, adult) matrix model of a similar form to that developed for Seychelles magpie robins (Copsychus sechellarum) (Norris \& McCulloch 2003). Stage-specific fecundities were derived from the annual productivity estimates generated by the individual-based stochastic simulation model (section 2.4.3). Stage-specific survival rates were estimated from existing data (see online Appendix 1) and assumed equal across the different management treatments as the study was conducted in a small region with the same habitat and 
environmental conditions. Individuals began breeding at 1 year of age, and we assumed that productivity was similar for yearling and adult females. We assumed survival rates were similar across our rat management treatments as to the best of our knowledge rats do not predate adult olive white-eyes on the nest, so any differences in PMR between treatments reflect differences in stage-specific fecundities.

\section{Results}

\subsection{Rat Management}

The results of rat snap-trapping show that the presence of poison had a significant effect on rat abundance in September $\left(x^{2}=6.9021\right.$, d.f. $\left.=1, P=0.008\right)$, two months after poison initiation, with the average CPUE reduced by $23 \%$ with Trap management compared with a reduction of $92 \%$ with Poison management. Poison had no significant effect on the CPUE across the whole breeding season $\left(x^{2}=\right.$ 4.6768, d.f. $=3, P=0.197)$ or four $\left(X^{2}=0.2619\right.$, d.f. $\left.=1, P=0.609\right)$ and six $\left(X^{2}=\right.$ 2.1416 , d.f. $=1, P=0.143$ ) months after initiation. Area also had no significant impact on CPUE at two $\left(X^{2}=0.5136\right.$, d.f. $\left.=1, P=0.474\right)$, four $\left(X^{2}=1.5836\right.$, d.f. $=2, P=$ $0.453)$ or six months $\left(X^{2}=2.6374\right.$, d.f. $\left.=2, P=0.268\right)$.

\subsection{Nesting Success}

Rat management had a significant effect on $\mathrm{DNS}_{\mathrm{N}}$ increasing survival from $85 \%$ with Control management to $93 \%$ and $98 \%$ with Trap and Poison management, respectively (Fig. 2). The effect of management on DNS, was not significant, averaging at $97 \%( \pm 0.02)$ across all three rat management techniques. There was no evidence to suggest that either nest characteristics or vegetation structure influenced management and therefore had no impact on its measure of DNS. When combining the rat management treatments to see the impact of poisoning alone on $D N S_{\text {। }}$ and $D_{N S}$ no significant difference was found. All model outcomes can be found in Table 2.

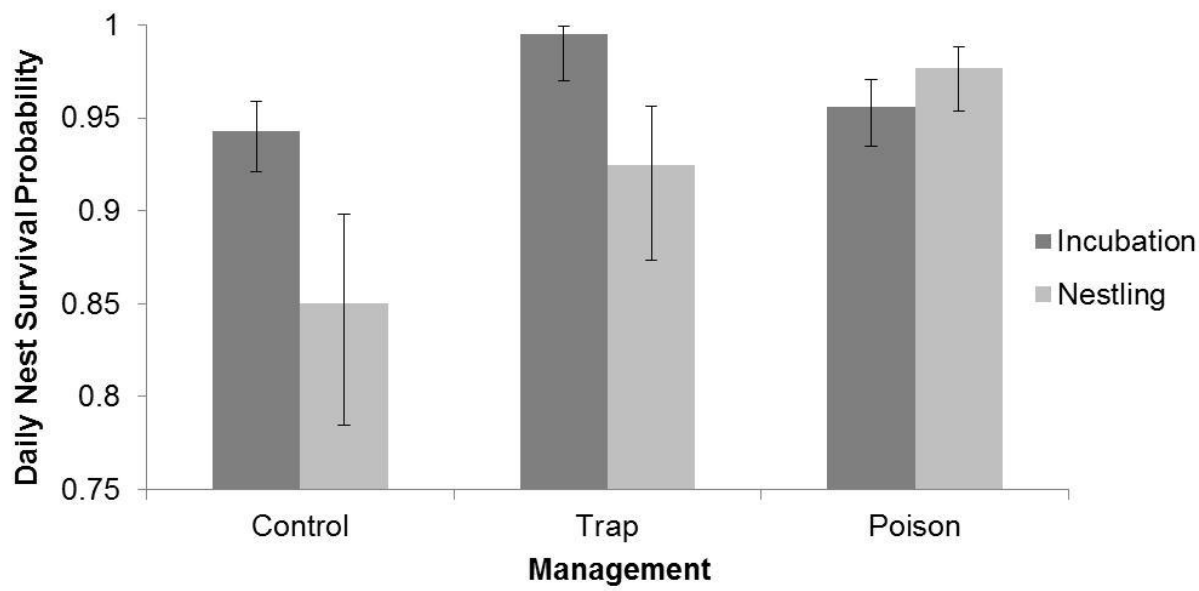

Fig. 2. Daily nest survival of Mauritius olive white-eye nests in Combo during the incubation and nestling stage in the $2010 / 11$ breeding season under varying rat management techniques; No management (Control), snap-trapping alone (Trap) and rat poisoning and snap-trapping (Poison). Bars represent standard error.

\section{Table 2.}

Results using a generalised linear mixed model (GLMM) examining daily nest survival during the incubation and nestling stages $\left(D N S_{/} / D N S_{N}\right)$ separately in relation to rat management (Management; Control (no management), Trap (snap-trapping alone) and Poison (snap-trapping and rat poisoning)) and investigating rat management as a two and three level factor to assess the impact of rat poisoning 
alone (Trap + Poison). Also, the results using Chi-squared tests examining the effect of nest characteristics (Nest height $(\mathrm{m})$, Position (position in canopy: upper, middle, lower) and Density (density of vegetation around the nest: dense, sparse)) and vegetation structure measures (Understory (understory density: dense, medium, sparse) and Canopy (canopy density: dense, medium, sparse)) on management to investigate if these factors would impact the influence of management on DNS, or $\mathrm{DNS}_{\mathrm{N}}$. Our small sample size precluded the fitting of complex multivariate GLMMs for these factors.

\begin{tabular}{|c|c|c|c|c|c|}
\hline Factor & Model & $\mathrm{DNS}_{/} / \mathrm{DNS}_{\mathrm{N}}$ & $x^{2}$ & d.f. & $\begin{array}{c}P \text {-value } \\
\left({ }^{*}<0.05\right)\end{array}$ \\
\hline \multirow[t]{2}{*}{ Management } & GLMM & $\mathrm{DNS}_{\mathrm{I}}$ & 0.2444 & 2 & 0.88 \\
\hline & & $\mathrm{DNS}_{\mathrm{N}}$ & 6.8596 & 2 & $0.03^{*}$ \\
\hline \multirow[t]{2}{*}{ Nest height } & $\begin{array}{c}\text { Chi- } \\
\text { squared }\end{array}$ & $\mathrm{DNS}_{\mathrm{I}}$ & 38.3154 & 36 & 0.36 \\
\hline & & $\mathrm{DNS}_{\mathrm{N}}$ & 21.6389 & 24 & 0.60 \\
\hline \multirow[t]{2}{*}{ Position } & $\begin{array}{c}\text { Chi- } \\
\text { squared }\end{array}$ & $\mathrm{DNS}_{\mathrm{I}}$ & 2.7388 & 2 & 0.25 \\
\hline & & $\mathrm{DNS}_{\mathrm{N}}$ & 6.3402 & 4 & 0.18 \\
\hline \multirow[t]{2}{*}{ Density } & $\begin{array}{c}\text { Chi- } \\
\text { squared }\end{array}$ & $\mathrm{DNS}_{\mathrm{I}}$ & 7.749 & 4 & 0.10 \\
\hline & & $\mathrm{DNS}_{\mathrm{N}}$ & 4.8431 & 2 & 0.08 \\
\hline \multirow[t]{2}{*}{ Understory } & $\begin{array}{c}\text { Chi- } \\
\text { squared }\end{array}$ & $\mathrm{DNS}_{\mathrm{I}}$ & 1.2086 & 4 & 0.88 \\
\hline & & $\mathrm{DNS}_{\mathrm{N}}$ & 3.9238 & 4 & 0.42 \\
\hline \multirow[t]{2}{*}{ Canopy } & $\begin{array}{c}\text { Chi- } \\
\text { squared }\end{array}$ & $\mathrm{DNS}_{\mathrm{I}}$ & 2.9256 & 4 & 0.57 \\
\hline & & $\mathrm{DNS}_{\mathrm{N}}$ & 4.0212 & 4 & 0.40 \\
\hline Trap +Poison & GLMM & $\begin{array}{l}\text { DNS }_{\text {I }} \\
\text { DNS }_{N}\end{array}$ & $\begin{array}{l}0.0554 \\
0.2034\end{array}$ & $\begin{array}{l}1 \\
1\end{array}$ & $\begin{array}{l}0.81 \\
0.65\end{array}$ \\
\hline
\end{tabular}

3.3 Annual Productivity

The individual-based stochastic simulation model showed that with the use of rat management the mean annual productivity of females can be increased substantially. Areas without management, i.e. Control management, produced 0.2 fledglings per female per breeding season, whereas Trap and Poison management produced an additional $0.57(95 \%$ C.I. $=0.55-0.59)$ and $0.9(95 \%$ C.I. $=0.88-0.92)$ fledglings, respectively. Sensitivity testing of the model parameters showed all the parameters responded to the changes. However, certain parameters $\left(\mathrm{DNS}_{\mathrm{N}}\right.$, nestling period and re-nesting probability following success) resulted in a greater change in annual productivity than others (Fig. 3). 


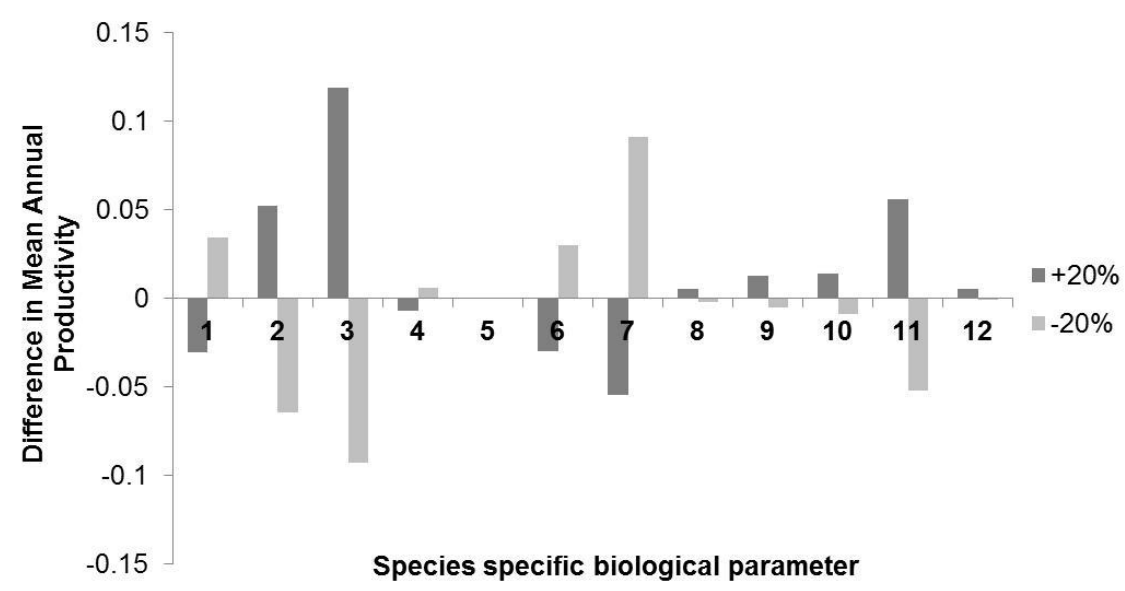

Fig. 3. Sensitivity testing of the individual based stochastic simulation model illustrating the difference in mean female Mauritius olive white-eye productivity for each parameter adjusted by $\pm 20 \%$; Initial first egg date (days) (1), Daily nest survival during incubation (2), Daily nest survival during nestling (3), Building duration (days) (4), Maximum number of successful nests (5), Incubation period (days) (6), Nestling period (days) (7), Egg hatching probability (8), Nestling fledging probability (9), Clutch size (10), Re-nesting probability following success (11) and Re-nesting probability following failure (12). Parameter 5 is a fixed value so was not altered. The Control territory parameter values were used as the base model.

\subsection{Population Multiplication Rate}

The two-stage matrix model predicted that the PMR increases with the addition of rat management. With Control management the PMR is negative with an annual population decline of $14 \%$. With Trap management the PMR becomes positive, with a predicted annual population increase of $1 \%$ and with the addition of rat poisoning with Poison management it increases further to $10 \%$ per year (Fig. 4).

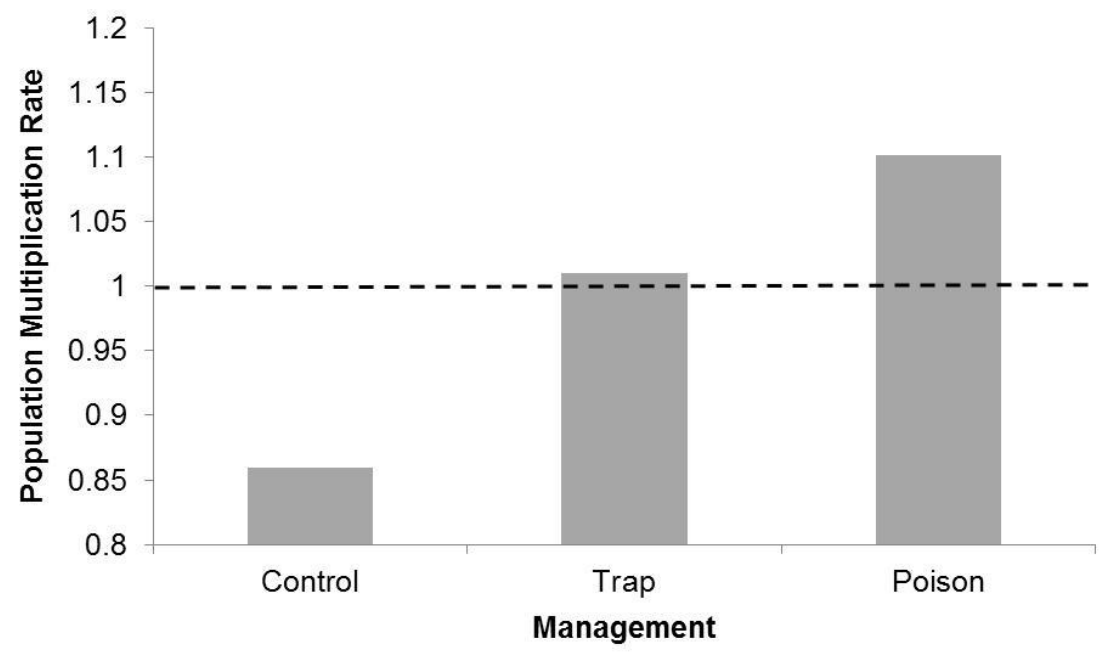

Fig. 4. The multiplication rate of the Combo Mauritius olive white-eye population under different rat management techniques; No management (Control), snaptrapping alone (Trap) and rat poisoning and snap-trapping (Poison). Values were generated from a hazard analysis with the dashed line indicating a stable population; values above 1 represent an increase and below 1 a decrease in population multiplication rate.

\section{Discussion}

\subsection{Rat Management}


By using the Nelson and Clark (1973) methodology to generate an unbiased, accurate index of rat abundance our study has shown that the application of rat poison in olive white-eye territories can significantly decrease rat abundance within the first two months of poison application. However, there was no evidence in the subsequent two and four months of a sustained low level of rat abundance, due primarily to fluctuations. One possible explanation for these fluctuations is that poison removes resident rat populations from the area but it is subsequently re-colonised through immigration from the surrounding rat home-ranges. There is evidence to support this from a long-term study of rats on mainland Mauritius (Hall, 2003). A second possible explanation is that there might be natural annual fluctuations in rat abundance in response to rat breeding cycles, stochastic events or environmental factors which could influence the impact of rat poisoning (Alterio et al., 1999; Hall, 2003). However, with relatively small sample sizes and limited short-term data from the study system at Combo these results are preliminary and we are unable to account for these factors in our analyses or explore them in any detail. Therefore, this study should be repeated and these natural fluctuations in rat abundance and the impact of re-colonisation should be considered in any future rat management techniques, with rat management implemented during high levels of natural rat abundance (October -December) and periods of peak olive white-eye breeding activity (September-November) (Hall, 2003; Maggs et al., 2011).

The size of the management area and treatment density did not affect the CPUE, however, the olive white-eye territories are small and closely distributed within the Combo region and so there is a risk of rats moving across numerous treatment sites and influencing the impact of management. Territories were allocated treatments randomly to avoid bias and most of the treatment territories were independent of each other. However, some of the territories with Trap management were adjoining which may have influenced the rate of rat re-colonization and underestimated the CPUE, masking the impact of Trap management on an individual territory basis. In Mauritius the home range of rats vary between $0.3-0.4$ ha (Hall, 2003) which is less than the average olive white-eye breeding territory $(0.5 \mathrm{ha})$ and rat home range sizes are not found to change in response to poisoning (Hall, 2003). It is therefore unlikely that rats would travel across numerous territories or alter their territorial behaviour in response to management and influence the impact of the treatment.

Other studies investigating the impact of management on rat abundance, in relation to threatened passerine populations, have found that the use of rat poison can decrease rat abundance however, these studies also encountered re-colonisation effects indicating that small scale management may not be the most effective method over prolonged periods (Blanvillain et al., 2003; Rocamora and Baquero, 2007; Vanderwerf and Smith, 2002).

\subsection{Nesting Success}

Analysis of DNS has shown that the use of rat management can significantly increase $\mathrm{DNS}_{\mathrm{N}}$ through rat poisoning and snap-trapping or snap-trapping alone. As suggested by Nicoll and Norris (2010) by conducting a robust field experiment which involved the simultaneous monitoring of both prey and predator species we have gained compelling evidence that there was a concurrent decline in rat abundance and improvement in $\mathrm{DNS}_{\mathrm{N}}$ during periods of rat management. Although there were fluctuations in rat abundance across the breeding season the periods of low CPUE overlapped with the peak in nesting attempts at nestling stage (October; Fig. A2), which could account for the impact on $D N S_{N}$. However, rat management failed to increase nesting success during incubation. This could be due to the secretive and elusive behaviour that olive white-eye display during the incubation period causing rats to overlook the nests. Once the nestlings have hatched the pairs become far 
more vocal and active around the nest as well as vocalization by the nestlings. Therefore, rats are potentially more likely to find the nests during this period causing a higher rate of predation and hence a positive impact of management.

A small proportion of territories with Trap management in the study were adjoining, potentially reducing the rate of rat re-colonization into the territories and causing the impact of Trap management on $\mathrm{DSN}_{N}$ to be overestimated. However, as previously discussed rat home-range sizes in Mauritius are on average smaller than olive whiteeye breeding territories and do not change in response to rat management and so it is unlikely that they would travel across numerous territories in one evening and influence the impact of the treatment (Hall, 2003).

As with the rat abundance data our sample sizes for this analysis are relatively small and due to logistical and financial restraints our nesting data only represents one breeding season. Although small-scale field experiments can assist in understanding the response of nesting attempts to different levels of management they are preliminary and cannot directly predict the population level or long-term implications, which are essential when designing more cost-effective management (Hiraldo et al., 1996; Pease and Grzybowski, 1995). Therefore, population-level impact and annual variation were not accounted for through direct field observations but instead predicted using demographic models. The impact of rat management on $\mathrm{DNS}_{\mathrm{N}}$ indicates that rats are a major limiting factor to the mainland population, highlighting the positive impact rat management can have on olive white-eye nesting success. Other studies investigating the effect of rat management on nesting success in threatened passerine species support our findings having also found that it can increase nesting success thus, providing further evidence that rats are a global limiting factor for threatened island passerine populations (Fessl et al., 2010; Innes et al., 1999; Robertson et al., 1994).

\subsection{Annual Productivity}

By using an individual-based stochastic simulation model, as opposed to a simple scalar model for example (Etterson et al., 2011), we have shown that the increase in nesting success is large enough to improve annual productivity of the olive white-eye population with both Trap and Poison management in spite of any effect of re-nesting compensation.

The results of the models are based on parameters collected from two olive whiteeye populations in contrasting habitats under different management and monitoring regimes; a mainland population and a supplementary fed, reintroduced subpopulation on a rat-free island nature reserve. This is due to the rarity of the olive white-eye and limited life history data available for the mainland population; a problem encountered by other projects studying declining, data deficient species (Fessl et al., 2010). However, sensitivity testing conducted on the model found the only parameters sensitive to change were those derived from the mainland study population; $\mathrm{DNS}_{\mathrm{N}}$, length of nestling period and re-nesting probability following success. This indicates that the island derived parameters do not have the greatest impact on the model and are therefore less influential.

Previous studies, calculating annual productivity, support our findings, yet the combination of DNS analysis and simulation models is seldom used for passerine populations yet is necessary in generating accurate annual productivity values for multi-brooded species and investigating the population level consequences of management (Fessl et al., 2010; Paradis et al., 2000; Pease and Grzybowski, 1995; Thompson et al., 2001; White, 2009). 


\subsection{Population Multiplication Rate}

The results of the two-stage matrix model show that without rat management the population decline is predicted to continue however, this can be prevented through the application of rat management within breeding territories. Trap management (snap-trapping alone) can lead to a population increase however the PMR remains close to 1 making it susceptible to negative impacts elsewhere or errors in parameterisation. In territories with Poison management (poison and snap-trapping) the PMR is substantially higher than 1 leading to an increased more robust population, preventing population decline and potential localised extinction. These results highlight the importance of investigating both the short and long-term impact of rat management techniques, as the addition of poison in territories had large implications for the long-term viability of the population; a factor which may have been overlooked on a small-scale.

Due to the design of the experiment, management sites differed in density where territories with Poison management ( $25 \mathrm{~m}$ spacings between snap-traps and poison stations) were twice the density of those with Trap management (50 m spacings between snap-traps). This design enabled rat abundance to be monitored at the same density and the impact of additional poison to be investigated, a method which has been used in other studies (Vanderwerf et al., 2011). However, if rat snaptrapping was conducted at $25 \mathrm{~m}$ instead of $50 \mathrm{~m}$ to match the density of Poison management we may have seen an increase in its effect. The application of these management techniques should be investigated further, applying them at the same density and investigating the impact of poisoning alone. This could enable the most effective technique to be identified, biologically, logistically and financially and allow further studies to be trialled e.g. investigating large-scale against small-scale or increasing the intersection lengths.

Studies researching threatened species tend to focus on the short-term impact of management and on a small, localised scale and so the long-term effects are less understood or misinterpreted (Baillie et al., 2000; Paradis et al., 2000). Therefore, hazard analysis using population matrix-models could be an important conservation tool for predicting the long-term implications of conservation management based on accurate short-term data, specifically the impact of rat management on threatened passerine populations (Armstrong et al., 2014; Norris and McCulloch, 2003).

\section{Conclusion}

Our findings have confirmed rats as a major limiting factor for the mainland population of olive white-eye. However, we have demonstrated that the application of rat management in breeding territories can significantly decrease rat abundance and significantly increase $\mathrm{DNS}_{\mathrm{N}}$. At a population level the use of rat management can increase annual productivity, leading to apparent population stability or increase. This highlights the immediate need for rat management in the mainland olive white-eye population to ensure their continued survival. With growing numbers of species on the verge of extinction and limited resources accurately assessing the impact of management techniques is essential (Bottrill et al., 2008). Here we demonstrate a conservation tool which enables the assessment of short-term management techniques and predicts its long-term impact allowing management to be refined and conservation resources to be allocated effectively to prevent potential localised extinction.

\section{Acknowledgements}

The olive white-eye recovery project is conducted by the Mauritian Wildlife Foundation in conjunction with the National Parks Conservation Services (Government of Mauritius). The authors would like to thank the two anonymous 
referees for helpful comments on earlier drafts and the following volunteer field biologists who helped to conduct this study - Tara Proud, Alistair Baxter and Megan Whittaker. Gwen Maggs is funded by Chester Zoo.

\section{References}

ALTERIO, N., MOLLER, H. \& BROWN, K. 1999. Trappability and densities of stoats (Mustela erminea) and ship rats (Rattus rattus) in a South Island Nothofagus forest, New Zealand. New Zealand Journal of Ecology, 23, 95-100.

ARMSTRONG, D.P., RAEBURN, E.H., LEWIS, R.M. \& RAVINE,D. 2006. Estimating the viability of a reintroduced New Zealand Robin population as a function of predator control. Journal of Wildlife Management, 70, 1020-1027.

ARMSTRONG, D. P., GORMAN, N., PIKE, R., KREIGENHOFER, B., MCARTHUR, N., GOVELLA, S., BARRETT, P. \& RICHARD, Y. 2014. Strategic rat control for restoring populations of native species in forest fragments. Conserv Biol, 28, 713-23.

ATKINSON, I. A. E. 1977. A reassessment of factors, particularly Rattus rattus L., that influenced the decline of endemic forest birds in the Hawaiian Islands. Pacific Science, 31, 109-133.

ATKINSON, I. A. E. 1985. The spread of commensal species of Rattus to oceanic islands and their effects on island avifaunas. In: MOORS, P. J. (ed.) Conservation of island birds. ICBP Technical Publication No. 3.

ATKINSON, I. A. E. 1989. Introduced Animals and Extinctions. New York: Oxford University Press.

BAILLIE, S. R., SUTHERLAND, W. J., FREEMAN, S. N., GREGORY, R. D. \& PARADIS, E. 2000. Consequences of large-scale processes for the conservation of bird populations. Journal of Applied Ecology, 37, 88-102.

BASSE, B., FLUX, I. \& INNES, J. 2003. Recovery and maintenance of North Island kokako (Callaeas cinerea wilsoni) populations through pulsed pest control. Biological Conservation, 109, 259-270.

BATES, D., MAECHLER, M., BOLKER, B. \& WALKER, S. 2013. Linear mixed-effects models using Eigen and S4 [Online]. Available: http://CRAN.Rproject.org/package=Ime4. (Accessed 31 July 2013)

BEINTEMA, A. J. \& MUSKENS, G. J. D. M. 1987. Nesting success of birds breeding in Dutch agricultural grasslands. Journal of Applied Ecology, 24, 743-758.

BIRDLIFE INTERNATIONAL. 2004. Threatened birds of the world 2004. CD-ROM. Cambridge: Birdlife International.

BIRDLIFE INTERNATIONAL. 2015. IUCN Red List for birds [Online]. Available: http://www.birdlife.org (Accessed 17 March 2015)

BLACKBURN, T. M., ESSL, F., EVANS, T., HULME, P. E., JESCHKE, J. M., KÜHN, I., KUMSCHICK, S., MARKOVÁ, Z., MRUGAŁA, A., NENTWIG, W., PERGL, J., PYŠEK, P., RABITSCH, W., RICCIARDI, A., RICHARDSON, D. M., SENDEK, A., VILÀ, M., WILSON, J. R. U., WINTER, M., GENOVESI, P. \& BACHER, S. 2014. A unified classification of alien species based on the magnitude of their environmental impacts. PLoS Biol, 12, 1-11.

BLANVILLAIN, C., SALDUCCIA, J. M., TUTURURAIA, G. \& MAEURAA, M. 2003. Impact of introduced birds on the recovery of the Tahiti Flycatcher (Pomarea nigra), a critically endangered forest bird of Tahiti. Biological Conservation, 109, 197-205.

BOTTRILL, M. C., JOSEPH, L. N., CARWARDINE, J., BODE, M., COOK, C., GAME, E. T., GRANTHAM, H., KARK, S., LINKE, S., MCDONALD-MADDEN, E., PRESSEY, R. L., WALKER, S., WILSON, K. A. \& POSSINGHAM, H. P. 2008. Is conservation triage just smart decision making? Trends Ecol Evol, 23, 649-54.

BROOK, B.W. \& KIKKAWA, J. 1998. Examining threats faced by island birds: a population viability analysis on the Capricorn silvereye using long-term data. Journal of Applied Ecology, 35, 491-503.

CHEKE, A. S. 1987. The ecology of the smaller land birds of Mauritius. In: DIAMOND, A. W. (ed.) Studies of Mascarene Land Birds. Cambridge: Cambridge University Press. 
COLE, R., TATAYAH, V. \& JONES, C. 2007. Mauritian Wildlife Foundation Passerine Report 2006-07. Mauritius: Mauritian Wildlife Foundation.

COLE, R., TATAYAH, V. \& JONES, C. 2008. Mauritian Wildlife Foundation Olive white-eye Recovery Program Annual Report 2007 - 2008. Mauritius: Mauritian Wildlife Foundation.

CORELL, H., MOKSNES, P. O., ENGQVIST, A., DÖÖS, K. \& JONSSON, P. R. 2012. Depth distribution of larvae critically affects their dispersal and the efficiency of marine protected areas. Marine Ecology Progress Series, 467, 29-46.

CUNNINGHAM, D.M. \& MOORS, P.J. 1996. Guide to the identification and collection of New Zealand rodents. Wellington, New Zealand.

ELLIOTT, G. P., MERTON, D. V. \& JENSEN, D. W. 2001. Intensive management of a critically endangered species: the kakapo. Biological Conservation, 99, 121-133.

ETTERSON, M. A., BENNETT, R. S., KERSHNER, E. L. \& WALK, J. W. 2009. Markov chain estimation of avian seasonal fecundity. Ecological Applications, 19, 622-630.

ETTERSON, M. A., ELLIS-FELEGE, S. N., EVERS, D., GAUTHIER, G., GRZYBOWSKI, J. A., MATTSSON, B. J., NAGY, L. R., OLSEN, B. J., PEASE, C. M., VAN DER BURG, M. P. \& POTVIEN, A. 2011. Modeling fecundity in birds: Conceptual overview, current models, and considerations for future developments. Ecological Modelling, 222, 2178-2190.

FESSL, B., YOUNG, G. H., YOUNG, R. P., RODRIGUEZ-MATAMOROS, J., DVORAK, M., TEBBICH, S. \& FA, J. E. 2010. How to save the rarest Darwin's finch from extinction: the mangrove finch on Isabela Island. Philos Trans R Soc Lond B Biol Sci, 365, 1019-30.

GRZYBOWSKI, J. A. \& PEASE, C. M. 2005. Renesting determines seasonal fecundity in songbirds: What do we know? What should we assume? The Auk, 122, 280-291.

HALL, D. G. 2003. The ecology of black rats Rattus rattus on Mauritius, and how their management affects native birds. Doctor of Philosophy, University of Bristol.

HAZLER, K. R. 2004. Mayfield logistic regression: a practical approach for analysis of nest survival. The Auk, 121, 707-716.

HIRALDO, F., NEGRO, J. J., DONAZAR, J. A. \& GAONA, P. 1996. A demographic model for a population of the endangered lesser kestrel in southern Spain. Journal of Applied Ecology, 33, 1085-1093.

INDIA 2013. Megalon Wax Blocks: Ready-for-use rodenticidal wax blocks based on Bromadiolone. Italy: I.N.D.I.A. Industrie Chimiche S.p.A.

INNES, J., HAY, R., FLUX, I., BRAD, P., SPEED, H. \& JANSEN, P. 1999. Successful recovery of North Island kokako Callaeas cinerea wilsoni populations, by adaptive management. Biological Conservation, 87, 201-214.

ISLAND CONSERVATION. 2012. Database of Island Invasive Species Eradications [Online]. Available: <http://eradicationsdb.fos.auckland.ac.nz/>. (Accessed 18 December 2013)

IUCN. 2013. IUCN Red List of Threatened Species [Online]. Available: www.iucnredlist.org. (Accessed 12 December 2013)

IUCN. 2014. IUCN Red List of Threatened Species [Online]. Accessed: www.iucnredlist.org (Accessed 15 February 2015)

JAMES, R. E. \& CLOUT, M. N. 1996. Nesting success of New Zealand pigeons (Hemiphaga novaeseelandiae) in responce to a rat (Rattus rattus) poisoning programme at Wenderholm Regional Park. New Zealand Journal of Ecology, 20, 45-51.

JETZ, W., THOMAS, G., JOY, J., REDDING, D., HARTEMANN, K. \& MOOERS, A. 2014. EDGE Birds priority list. London: Zoological Society of London.

KING, W. B. 1985. Island birds: will the future repeat the past? In: M. P. J (ed.) Conservation of Island Birds. ICBP Technical Publication.

LUDWIG, M., SCHLINKERT, H., HOLZSCHUH, A., FISCHER, C., SCHERBER, C., TRNKA, A., TSCHARNTKE, T. \& BATÁRY, P. 2012. Landscape-moderated bird nest predation in hedges and forest edges. Acta Oecologica, 45, 50-56. 
MAGGS, G., TATAYAH, V. \& JONES, C. 2009. Mauritius Olive White-Eye Annual Report 2008-09. Mauritius: Mauritian Wildlife Foundation.

MAGGS, G., ZUËL, N., TATAYAH, V. \& JONES, C. 2010. Mauritius Olive White-eye Annual Report 2009-10. Mauritius: Mauritian Wildlife Foundation.

MAGGS, G., ZUËL, N., TATAYAH, V. \& JONES, C. 2011. Mauritius Olive White-eye Annual Report 2010-11. Mauritius: Mauritian Wildlife Foundation.

MATTSSON, B. J. \& COOPER, R. J. 2007. Which life-history components determine breeding productivity for individual songbirds? A case study of the Louisiana waterthrush (Seiurus motacilla). The Auk, 124, 1186-1200.

MAYFIELD, H. 1961. Nesting success calculated from exposure. The Wilson Bulletin, 73, 255-261.

MAYFIELD, H. 1975. Suggestions for calculating nesting success. The Wilson Bulletin, 87, 456-466.

MOORHOUSE, R., GREENE, T., DILKS, P., POWLESLAND, R., MORAN, L., TAYLOR, G., JONES, A., KNEGTMANS, J., WILLS, J., PRYDE, M., FRASER, I., AUGUST, A. \& AUGUST, C. 2003. Control of introduced mammalian predators improves kaka Nestor meridionalis breeding success: reversing the decline of a threatened New Zealand parrot. Biological Conservation, 110, 33-44.

NAGY, L. R. \& HOLMES, R. T. 2004. Factors influencing fecundity in migratory songbirds: is nest predation the most important? Journal of Avian Biology, 35, 487-491.

NELSON, L. \& CLARK, F. W. 1973. Correction for sprung traps in catch/effort calculations of trapping results. Journal of Mammology, 54, 295-298.

NICHOLS, R., WOOLAVER, L. \& JONES, C. 2004. Continued decline and conservation needs of the endangered Mauritius olive white-eye Zosterops chloronothos. Oryx, 38, 291-296.

NICHOLS, R., WOOLAVER, L. \& JONES, C. 2005. Breeding biology of the endangered Mauritius olive white-eye Zosterops chloronothos. Ostrich, 76, 1-7.

NICOLL, M. \& NORRIS, K. 2010. Detecting an impact of predation on bird populations depends on the methods used to assess the predators. Methods in Ecology and Evolution, 1, 300-310.

NORRIS, K. \& MCCULLOCH, N. 2003. Demographic models and the management of endangered species: a case study of the critically endangered Seychelles magpie robin. Journal of Applied Ecology, 40, 890-899.

PARADIS, E., BAILLIE, S. R., SUTHERLAND, W. J., DUDLEY, C., CRICK, H. Q. P. \& GREGORY, R. D. 2000. Large-scale spatial variation in the breeding performance of song thrushes Turdus philomelos and blackbirds T. merula in Britain. Journal of Applied Ecology, 37, 73-87.

PEASE, C. M. \& GRZYBOWSKI, J. A. 1995. Assessing the consequences of brood parasitism and nest predation on seasonal fecundity in passerine birds. The Auk, 112, 343-363.

POWELL, L. A., CONROY, M. J., KREMENTZ, D. G. \& LANG, J. D. 1999. A model to predict breeding-season productivity for multibrooded sondgbirds. The Auk, 116, 1001-1008.

R CORE TEAM. 2013. R: A Language and Environment for Statistical Computing [Online]. Vienna: R Foundation for Statistical Computing. Available: http://www.R-project.org/. (Accessed 1 May 2013)

ROBERTSON, H. A., HAY, J. R., SAUL, E. K. \& MCCORMACK, G. V. 1994. Recovery of kakerori: An endandgered forest bird of the Cook Islands. Conservation Biology, 8, 1078-1086.

ROCAMORA, G. \& BAQUERO, P. 2007. Rat control using poisoning and trapping techniques at the properties of the United Arab Emirates President (ex-tracking station \& Haut Barbarons) and trends in Seychelles white-eye numbers on Mahé, 2006-07. Réhabilitation des Ecosystèmes Insulaires Rapport annuel au secrétariat du FFEM. Deuxième année d'opérations 1/05/06 au 30/04/07. Seychelles: Island Conservation Society. 
SAFFORD, R. J. 1991. Status and ecology of the Mauritius fody Foudia rubra and the Mauritius olive white-eye Zosterops chloronothos: two Mauritius passerines in danger. Dodo, 27, 113-139.

SAFFORD, R. J. 1997a. Distribution studies on the forest-living native passerines of Mauritius. Biological Conservation, 80, 189-198.

SAFFORD, R. J. 1997b. A survey of the occurance of native vegetation remnants on Mauritius in 1993. Biological Conservation, 80, 181-188.

SAFFORD, R. J. \& HAWKINS, F. 2013. The Birds of Africa: Volume VIII: The Malagasy Region: Madagascar, Seychelles, Comores, Mascarenes. London: Christopher Helm.

STAUB, F. 1993. Fauna of Mauritius and associated Flora. Mauritius: Précigraph Ltd.

TATAYAH, R. V. V., HAVERSON, P., WILLS, D. \& ROBIN, S. 2007a. Trial of a new bait station design to improve the efficiency of rat Rattus control in forest at Black River Gorges National Park, Mauritius. Conservation Evidence, 4, 20-24.

TATAYAH, R. V. V., MALHAM, J. \& HAVERSON, P. 2007b. The use of copper strips to exclude invasive African giant land-snails Achatina spp. from echo parakeet Psittacula eques nest cavities, Black River Gorges National Park, Mauritius. Conservation Evidence, 4, 6-8.

THOMPSON, B. C., KNADLE, G. E., BRUBAKER, D. L. \& BRUBAKER, K. S. 2001. Nest success is not an adequate comparason estimate of avian reproduction. Journal of Field Ornithology, 72, 527-536.

TOWNS, D. R., ATKINSON, I. A. E. \& DAUGHERTY, C. H. 2006. Have the harmful effects of introduced rats on islands been exaggerated? Biological Invasions, 8, 863-891.

TRENT, R. M., SWINNERTON, K. J., GROOMBRIDGE, J. J., SPARKLIN, B., D, BROSIUS, C. N., VETTER, J. P. \& FOSTER, J., T 2008. Ground-based rodent control in a remote Hawaiian rainforest on Maui. Pacific Conservation Biology, 14, $206-214$.

UNDERWOOD, A. J. 1997. Experiments in Ecology: Their logical design and interpretation using analysis of variance. Cambridge: University Press.

VANDERWERF, E., A. \& SMITH, D., G. 2002. Effects of alien rodent control on demography of the O'ahu 'Elepaio, an endangered Hawaiian forest bird. Pacific Conservation Biology, 8, 73-81.

VANDERWERF, E.A., MOSHER, S.M., BURT, M.D., TAYLOR, P.E. \& SAILER, D. 2011. Variable efficacy of rat control in conserving Oahu elepaio populations. Gland, Switzerland: IUCN

WARREN, B. H., BERMINGHAM, E., PRYS-JONES, R. P. \& THEBAUD, C. 2006. Immigration, species radiation and extinction in a highly diverse songbird lineage: white-eyes on Indian Ocean islands. Mol Ecol, 15, 3769-86.

WEGGLER, M. 2006. Constraints on, and determinants of, the annual number of breeding attempts in the multi-brooded black redstart Phoenicurus ochruros. Ibis, 148, 273284.

WHITE, J. W., RASSWEILER, A., SAMHOURI, J. F., STIER, A. C. \& WHITE, C. 2013. Ecologists should not use statistical significance tests to interpret simulation model results. Oikos, 132, 385-388.

WHITE, P. J. C. 2009. Effects of agri-environmental and game management on the productivity of farmland passerines. Doctor of Philosophy, University of Reading. 